\title{
Treatment of wet and dry types of age-related macular degeneration
}

Age-related macular degeneration (AMD) is a common cause of blindness in developed regions. ${ }^{1}$ Late-stage AMD is categorized as the neovascular (wet) type and the atrophic (dry) type. Despite the availability of several potent drugs for the treatment of wet-type AMD, the problem of reducing treatment burden and enhancing treatment compliance remains a challenge. No proven treatments are available for dry-type AMD.

In this issue of the Hong Kong Journal of Ophthalmology, Kwok et $\mathrm{al}^{2}$ report the 2020 updates on recommendations for the treat-and-extend regimen for wet-type AMD. The authors recommend maintenance of treatment if there is no loss of $\geq 5$ ETDRS (Early Treatment Diabetic Retinopathy Study) letters, decreased intraretinal fluid, stable residual subretinal fluid $\leq 200 \mu \mathrm{m}$, no new macular hemorrhage, and no new neovascularization. The recommended criteria for extension or reduction of treatment can readily be derived from these maintenance criteria.

Also in this issue, Wong and $\mathrm{Kwok}^{3}$ review emerging treatments for dry-type AMD with geographic atrophy (GA). Both a phase 2 trial of a C3 inhibitor (intravitreal pegcetacoplan) and a phase 3 trial of a C5 inhibitor (intravitreal avacincaptad pegol) show positive results. Furthermore, results of two phase 3 trials of the $\mathrm{C} 3$ inhibitor (pegcetacoplan) have recently been announced by the manufacturer and presented orally at the Annual Meeting of the American Academy of Ophthalmology. ${ }^{4}$ The DERBY (621 patients enrolled) and OAKS (637 patients enrolled) trials are multicenter randomized double-masked shamcontrolled studies of the efficacy and safety of intravitreal pegcetacoplan in patients with GA secondary to AMD. After 12 months of monthly or every-other-month treatment with pegcetacoplan, OAKS showed a reduction in GA lesion growth of $22 \%(\mathrm{p}=0.0003)$ and $16 \%(\mathrm{p}=0.0052)$, respectively, whereas DERBY showed a reduction of $12 \%(\mathrm{p}=0.0528)$ and $11 \%(\mathrm{p}=0.0750)$, respectively, but did not meet the primary endpoint of GA lesion growth. Nonetheless, in a prespecified analysis of the combined studies, pegcetacoplan was shown to decrease GA lesion growth in patients with extrafoveal lesions by $26 \%(\mathrm{p}<0.0001)$ after monthly treatment and $23 \%(\mathrm{p}=0.0002)$ after every-other-month treatment. We look forward to formal peer-reviewed publication of the results of these trials.

Alvin KH Kwok, MD (HK), MD (CUHK), PhD (HK), FRCS (UK), FRCOphth (UK), FHKAM (Ophth), PostGrad DipEpidem \& Biostat (CUHK), MBBS (HK)

Department of Ophthalmology, The Hong Kong Sanatorium and Hospital, Hong Kong

Correspondence and reprint requests:

Dr Alvin KH Kwok, Department of Ophthalmology, 4/F, Li Shu Fan Block, The Hong Kong Sanatorium and Hospital, 2 Village Road, Hong Kong.

Email:alvinkhkwok@netvigator.com

\section{References}

1. Mitchell P, Liew G, Gopinath B, Wong TY. Age-related macular degeneration. Lancet 2018;392:1147-59. Crossref

2. Kwok AKH, Lam WC, Fong AHC, et al. Recommendations of the treat-and-extend regimen for neovascular agerelated macular degeneration: 2020 updates. Hong Kong $J$ Ophthalmol 2021;25:39-46. Crossref

3. Wong HL, Kwok AKH. Emerging treatments for dry age- related macular degeneration with geographic atrophy: a systematic review. Hong Kong J Ophthalmol 2021;25:4756. Crossref

4. Apellis Pharmaceuticals. Apellis announces top-line results from phase 3 DERBY and OAKS studies in geographic atrophy $(G A)$ and plans to submit NDA to FDA in the first half of 2022. Available from: https://investors.apellis.com/newsreleases/news-release-details/apellis-announces-top-lineresults-phase-3-derby-and-oaks. Accessed 29 Dec 2021. 